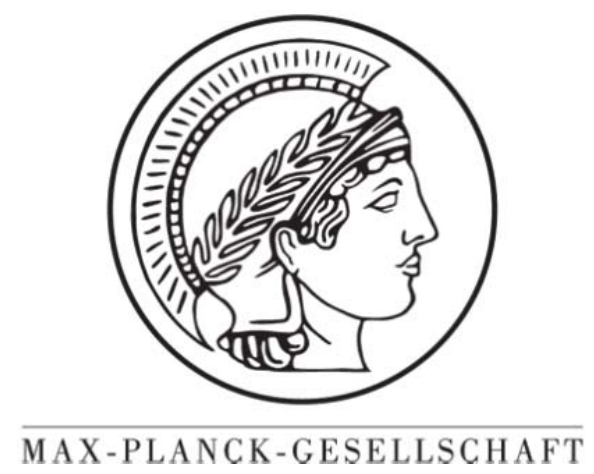

Originally published as:

Elmar Zeitler:

Chicago exploration days.

Ultramicroscopy, 2012, Vol. 123, pp. 13-21 


\title{
Chicago exploration days
}

\author{
Elmar Zeitler \\ Fritz-Haber-Institut der Max-Planck-Gesellschaft Faradayweg 4-6 D-1000 Berlin 33 (Dahlem), Germany
}

\section{A R T I C L E I N F O}

Available online 13 June 2012

Keywords:

Albert Crewe

High Voltage STEM

STEM image formation

\begin{abstract}
A B S T R A C T
Single heavy atoms supported on thin carbon film were first imaged by Crewe, Wall and Langmore with their dark-field STEM. This glimpse into a hitherto invisible world we owe undeniably to Crewe's vision and determination, and to his gift to electrify, engage and encourage talented students. Since this successful event happened during my sabbatical stay in Crewe's group, the editors of this memorial volume asked me to write an account of its early history, which I gladly composed mostly from memory.

The circumstances that led to my collaboration with Albert Crew in Chicago are reviewed, and the main project that we jointly embarked on the Chicago $1 \mathrm{MeV}$ STEM is described. It is shown that the project was nearing completion and would have likely been successful, had funding been continued. The paper concludes with a tribute to Albert I wrote many years ago.
\end{abstract}

(C) 2012 Published by Elsevier B.V.

\section{Introduction}

When the editors Michael Isaacson and Ondrej Krivanek, friends of long standing, encouraged me to contribute to the Memorial Volume for Albert Crewe a paper on the early days of his pioneering work in Scanning Electron Microscopy, I gave a rash and enthusiastic answer. Pondering about this commitment more soberly later on, I realized that for fifteen years I have held the title of professor emeritus, and now I am considered a wise man whose main function is to report on events that have occurred still another thirty years before.

I regained a calm state of mind after Google responded to my query "A.V. Crewe, Scanning microscope Argonne National Lab" with a most informative and helpful reply: "Chapter 1, The work of Albert Victor Crewe on the Scanning Transmission Electron Microscope and Related Topics, by A.V. Crewe, Advances in Imaging and Electron Physics Vol. 159, 1-61 (2009)".

The editor of this well-known series that was founded by the pioneer L.L. Marton is Peter Hawkes, who earned his Ph.D. with a thesis on Aberrations of Optical Systems without Rotational Symmetry in the group of V.E. Cosslett at the Cavendish Laboratory. ${ }^{1}$ Hawkes felt strongly that this Volume 159 dedicated to Cold Field Emission and the Scanning Electron Microscope must contain a contribution from Albert, whose health, unfortunately, did not allow this new effort.

We note, however, that Albert had already written two vivid accounts of his Chicago activities under the title Chicago

\footnotetext{
E-mail address: zr@fhi-berlin.mpg.de

${ }^{1}$ Historical footnote: the Microscope Society of America elected L.L. Marton and A.V. Crewe as Distinguished Scientists of 1976.
}

Aberrations. These, with Albert's approval, Peter included as Chapter 1 in Volume 159 of his Advances. I feel grateful to Albert and to Peter because they have already fulfilled my assignment, that is, to provide the community of microscopists an insight into those early days. Scholars with a keen sense for history I advise to turn to Albert's chapter; for the just curious ones, I continue my narrative as a supplement with some non-scientific, human details, with which I would like to recall the wonderful climate that prevailed in that period.

\section{Albert Crewe}

\subsection{Meeting Albert}

My interaction with Albert starts with the memorable workshop on High-Voltage Electron-Microscopy sponsored jointly by Argonne National Laboratory and the Associated Midwest Universities. The workshop lasted four (!) weeks from June 13 to July 14, 1966, enjoying the facilities of the Laboratory. Raymond Hart was the chairman and the responsible editor of the transcribed presentations. Up to sixty scientists of all kinds, including Albert, the Director of the Lab presented, tried out and discussed their ideas.

I still remember the car ride to which Albert had invited me to show the pleasant campus of the Lab. We also talked about personal things and so discovered that we both were European war-kids, he one month my senior, who had earned post-war Ph.D.'s in physics unrelated to electron microscopy. We both had been invited to the US on account of previous achievements. With every mile of our tour grew my appreciation for the weight of the 
responsibility that my coeval tour-guide had to carry, the responsibility for over one thousand employees!

Albert confided to me that he had already decided to return as Professor of Physics to the University of Chicago taking with him the students who had impressed us visitors and the microscopes under construction. In his Foreword to the Proceedings of the workshop published as National Laboratory Report ANL-7275 Albert formulates the reasons and expectations of his move: "There is one small octave of [object-] sizes inaccessible to date for inspection in the region of $1 \AA$. A tremendous analytical power will be available to us if we can achieve resolutions of $1 \AA$ or better. So here again is another primary reason for being interested in this kind of development." This is Albert's raison d'être. Now, in retrospect, we know that this was the case all his life. With this knowledge I begin my report with the summer of 1966.

The second epoch of collaboration with Albert and his group begins in September 1968 with negotiating and planning my sabbatical year 1969 at the University of Chicago. Wasn't it a wonderful idea of the Lyndon B. Johnson administration to grant sabbatical years to civil servants? As a government employee working as Assistant Chief in the Biophysics Branch of the Armed Forces Institute of Pathology in Washington D.C. I had applied and was permitted to spend one year with Albert and his group. During the European Conference on Electron Microscopy (1968) in Rome we could already sketch preliminary plans.

Finally, a third occasion for interaction and collaboration arose, this time closer and more intense than the previous ones, namely as a tenured colleague of Albert in the Departments of Physics and of Biophysics, and as member of the Enrico-Fermi Institute, University of Chicago. I now describe the two further phases in more detail.

\subsection{Exploration during my sabbatical year in Albert's group}

Having never experienced a sabbatical leave and still feeling a bit like a greenhorn in American Academia, I decided to visit the University of Chicago in October 1968. I found an apartment in Hyde Park four blocks away in walking distance from the lab, suitable to move there with my family, wife plus two children, 5 and 4, from Washington DC in the January of 1969. The year 1968 was that year of violence, Martin Luther King had been assassinated on April 4, Robert F. Kennedy had been shot on June 5 of that year. Serious riots erupted in August while the Democratic Convention was held in town.

On January $8 \mathrm{I}$ reported at the Enrico Fermi Institute. The Crewe labs were two large, adjacent rooms whose separating wall was generously removed. Here I found the students I already knew, Joe Wall was operating the so- called $5 \AA$ STEM, Mike Isaacson and Dale Johnson who had planed to fit an electronspectrometer to the minimized gun-microscope, so named, because it consisted really only of the two essential components, the field-emission electron gun and the high-vacuum ionpump [1]. Then there was Mike Thomson, a British postdoc who had been supervised by Peter Hawkes in Cambridge.

As center of activities served a coffee-urn percolating all day long, run by the group and supervised by Judith Reiffel, Albert's secretary, who later became a fondly remembered author in electron microscopy $[2,3]$. A rack with a collection of cups and a sufficient number of simple chairs, easily moved, fulfilled their purpose. Judith resided in a cubbyhole around the corner whereas Albert's office was right across the hall. He still lived far away, close to the Argonne lab. Avoiding the morning rush, he would arrive peppy with the desire for his first cup of coffee and for a discussion of new ideas that had popped up during his leisurely ride to work. This ritual often signaled the beginning of a new project. At the end of the hall was another small room that housed the tools, glassware, chemicals, etc. needed for fabricating the tungsten field-emitters, the tips. A dedicated high-vacuum rig, called the tip-tester, guaranteed that the virgin tips inserted into the active STEM behaved according to specification.

In order to enable the reader to form his own picture of the interactions of this lively group, three further facilities must be mentioned:

(1) In the proximity of the lab was a friendly conference-room for twenty or so persons, with comfortable chairs and equipped with all the means required for internal seminars or for presentations by guests or invited friends.

(2) An extraordinary workshop, in which the often demanding designs were transformed into functioning apparatus, was located in the basement under the lab. The service had to be paid for with money allotted by the granting agency.

(3) Close to the workshop was the entrance to the Computer Center, in which IBM-mainframe monsters waited for you to bring your deck of punched cards for successful crunching.

In this group I felt like a journeyman who wants to help and earn his living; my toolbox contained the manuals, e.g., the Discussion of Cross Sections of Possible Contrast Mechanisms in the Electron Microscope which I had presented at the Argonne Workshop, and which could be useful for future seminars. Also in the box was a hymnbook with our song on Quantitative Electron Microscopy:

"In most applications of the electron microscope the pictorial information is evaluated in qualitative terms of geometric features of the image elements and their mutual geometric relations. This information must be correlated with respectively the physical, chemical or biological data of the specimen. A quantitative aspect can, of course, be brought into this evaluation by either measuring distances or by counting the occurrences of certain structures on the micrograph. A complete morphological description must, however, include the third dimension, which is not as apparent as the two dimensions in the image plane. The thickness is however, presented "depicted" as it were, as image contrast, i.e., the recorded variation of the electron beam intensity after interaction with the matter of the object. Indeed, the third dimension "carries more weight" than the other two, since it determines the degree of interaction and thus the detectability of the other two. Provided the physical nature of the electron interaction within the specimen is known, the observed contrast can be considered a quantitative analog to the path length of that interaction. This concept has been referred to as Quantitative Electron Microscopy" [4].

The first weeks of this year will be remembered for their long and excited discussions; they were ignited by the latest images that Joe Wall had produced with his $5 \AA$ STEM. These images showed diffraction phenomena and phase-contrast fringes that were totally unexpected and for the time difficult to explain. Phase contrast in a STEM was the exciting puzzle! Mike Thomson and I decided that we as a team should aim at a Theory of Phase Contrast Formation in the STEM. In addition to the physical knowledge and the optical background required for our goal, Mike had a profound experience in programming and running computations, which I lacked.

In April Albert was scheduled to give a paper at the Second Annual Scanning Microscope Symposium here in town. He must have excited the audience with the very recent phase-contrast images which, however, were too late for the Proceedings (Fig. 1). They certainly must have had impressed John Cowley; as he mentions them in a note from May 261969 in Applied Physics Letters [5], where he also invokes the principle of reciprocity to formulate the imaging conditions for equal outputs of STEM and 


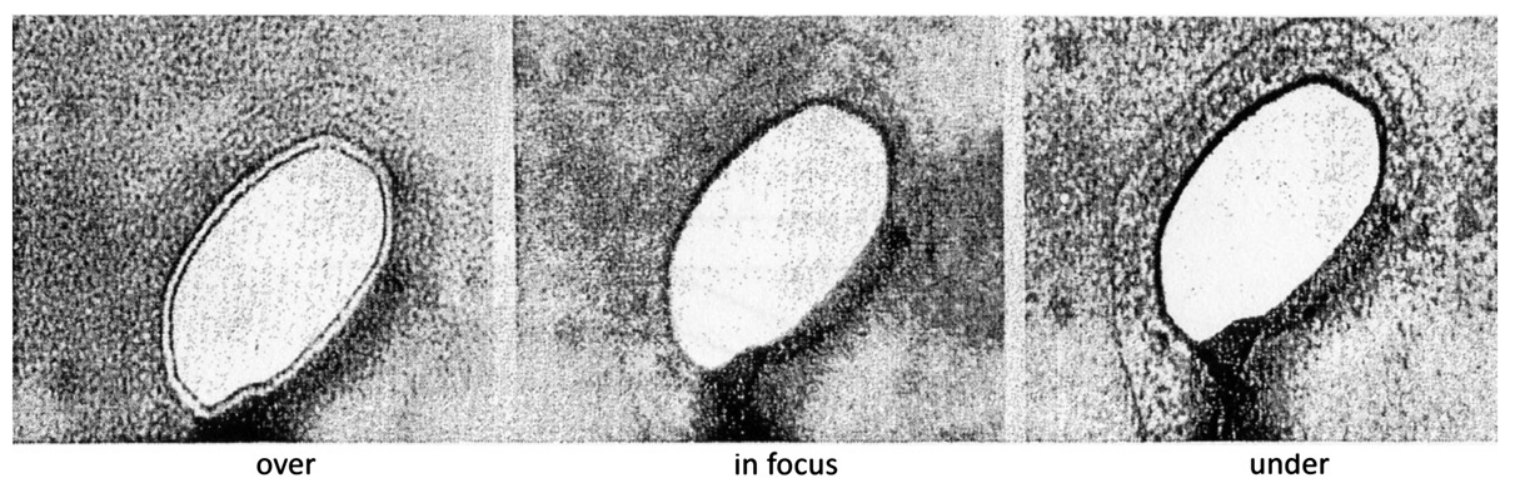

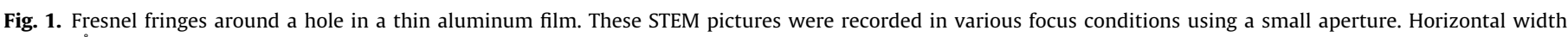
of $3100 \AA$ each.

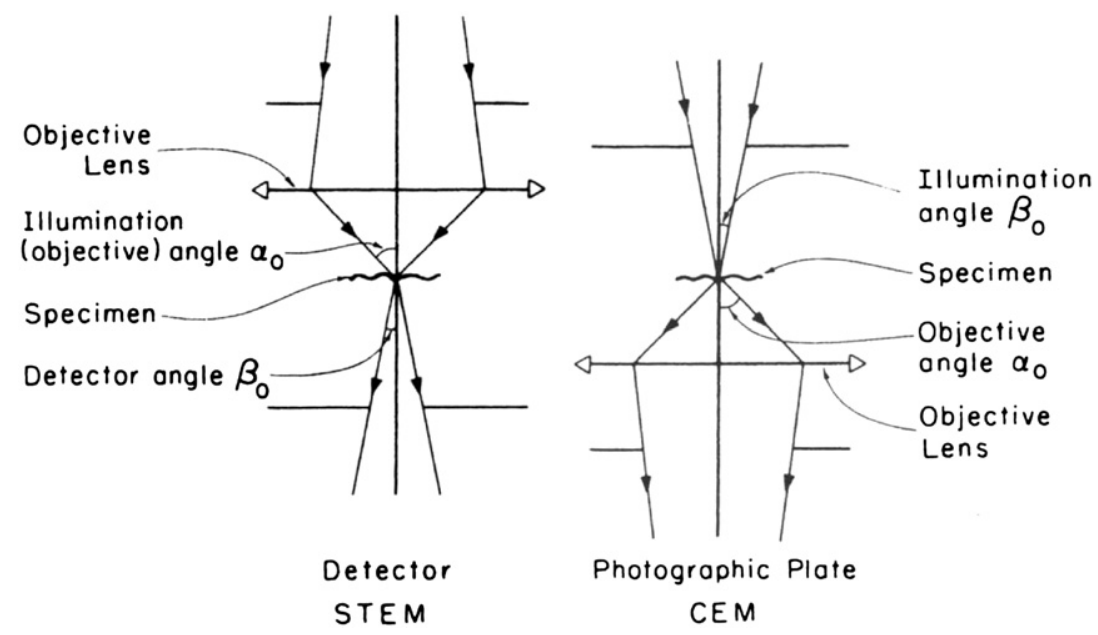

Fig. 2. Relations between corresponding angles that assure equivalent performance (reciprocity) [8].

CTEM (called just "CEM" at that time). In mid-July the above striking phase-contrast images were compiled and ready to go out to the waiting community in the publication Contrast in a High Resolution Scanning Transmission Electron Microscope by Crewe and Wall. Unfortunately, their publication in Optik took until May 1970 [6].

Reciprocity applies to a system whose input and output can be interchanged without altering the response to a given excitation. The application of the principle of reciprocity is very elegant but can it give the answer to questions of performance? You need to know the conditions for its validity; in our case it is valid only for amplitudes and not for intensities. It must be valid for the components as well; in our case the specimen is illuminated either from the front or from the back. As our motivation was to find the instrumental parameters and settings for optimum performance, Mike Thomson and I investigated the STEM in this way. The STEM can be best analyzed as a Projection Microscope by stopping the scanning probe on a single spot of the object. Depending on the location of the crossover of the illumination, away from or at the specimen, the Projection Microscope can be run as a shadow microscope or as a diffraction camera. Recording was possible either by direct photography or more conveniently by scanning the beam after passage through the object (as in Joe's machine), though nowadays the images would of course most likely be recorded by a CCD camera.

In our paper we could show that phase contrast formation in the STEM is governed by exactly the same equations as those for the CTEM. These equations thus determine the parameters that must be set for an equivalent performance of the two types of microscope (Fig. 2). In retrospect, our finding justifies the application of the principle of reciprocity for the proof of equivalence. Happily we submitted our paper to Optik on December 11, 1969 just before the end of my sabbatical year [7].

In an epilog to this section let me add that the many questions posed by our work but left unanswered, like the quality of the STEM performance, the achievable signal to noise ratio and the signal collection efficiency were treated by Mike Isaacson, Joe Wall, Mike Thomson [8] and by later members of the group, John Langmore [9] and Harald Rose [10].

\subsection{Exploration as Albert's colleague}

In the summer of 1970, the University of Chicago offered me a joint professorship in Physics and Biophysics, which I gladly accepted. The following January the family was back in Hyde Park and I had moved into the two rooms in the Fermi Institute designated as a part of my future lab. My new colleague Humberto Fernandez-Moran, Professor of Biophysics, had vacated the area, leaving a $100 \mathrm{kV}$ Hitachi HU-11 for my use, and more importantly, with it a most experienced operator and my later assistant Mitsui Ohtsuki. Humberto was well known internationally for his pioneering work on cryo-microtomy and as the inventor of the diamond knife [11]. During a longer scientific visit in 1955 to the Nobel Institute for Cell Research in Stockholm, Humberto had been my first instructor on an RCA Electron Microscope EML $50 \mathrm{kV}$. 


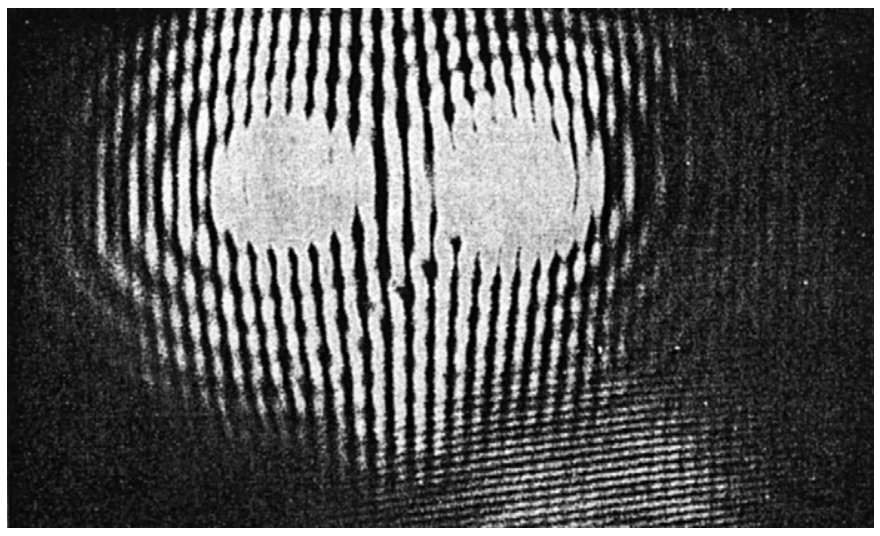

Fig. 3. Young's Double Hole Experiment with $75 \mathrm{kV}$ electrons [13] (note the finer fringe system produced by a more distant hole in the gold foil).

A second colleague, Professor Riccardo Levi-Setti, whom I knew as particle physicist from my first stay, is also known in paleontological circles for his research on trilobites. He had received his Ph.D. in 1949 at the University of Pavia, Italia; visiting Fermi had invited him to the $\mathrm{U}$ of $\mathrm{C}$ where he arrived in 1956 and is still today, in 2011, an active emeritus. Since I saw Riccardo last he had developed a great interest in particle optics, most likely prompted by Albert's gift of a field emission gun. Riccardo was determined to convert this electron gun into a proton gun. He and a few brilliant Ph.D. students [12] were successful in transforming the proton gun into a high-resolution microprobe capable of mapping the chemical composition of materials, be it in grains of alloys or in mitotic figures of chromosomes (SIMS).

As a very special welcome, Albert bestowed a pair of precious electrodes on me, so that I could assemble my own field-emitting electron (Butler) gun. Albert, Riccardo, two months my junior, and I formed a most congenial triumvirate, the guns our logo, high resolution our ambition.

Also waiting was a very motivated Ph.D. student with whom I had exchanged letters concerning our collaboration. Besides being an excellent student from MIT, Jesper Munch, a Dane, was a skilled mechanic and an experienced sailor; with his waving beard he looked like a Viking. In short, he was the ideal candidate for utilizing Albert's gift as a highly coherent electron source for holographic research [13] (Fig. 3).

Having informed the reader as to the circumstances, we shall now discuss the collaboration between Albert and myself in the next part of my report.

\section{Scanning transmission electron microscope}

\subsection{The $1 \mathrm{MeV}$ scanning transmission electron microscope}

The goal of our collaboration was, almost as a matter of course, to further the development of the STEM by utilizing the advantages of the scanning mode:

1. In contrast to the conventional (fixed beam) transmission electron microscope (CTEM), the electron beam in the STEM traverses the image-forming lenses before it loses energy through interacting with the specimen and is thus much less sensitive to chromatic aberration, which reduces the resolution and the maximum usable specimen thickness in the CTEM.

2. The sequential output facilitates the analysis and processing of the signal.
3. The very low electron beam current makes expensive radiation shielding unnecessary.

4. Scanners can be quite small as they need fewer lenses than conventional instruments and are therefore also less sensitive to external disturbances.

Our design was planned to fit into a regular laboratory room-a special building with cranes and heavy equipment usual for commercial High-Voltage CTEMs was not necessary.

Experimental biologists had already discovered the considerable potential of the High Voltage Electron Microscope to make contributions in biology. Professor Keith Porter had left Harvard to establish a laboratory for High Voltage Microscopy backed by the University of Colorado. He was convinced that the gain in penetration power would enable him to unravel the anatomy of whole cells, i.e., to elucidate the cytoskeleton [14]( see also [15]).

These are the reasons for our decision to write a grant proposal for the construction of a $1 \mathrm{MeV}$ STEM; also internal considerations led us to ask for support from the National Institute of Health. Thanks to Albert's pledge to be strongly involved, our proposal was funded by NIH Grant no. GM19070. Formally, I was named Principal Investigator, the following description of design details, however, makes Albert's handwriting readily recognizable. The grant was to run over five years on one dollar per $2 \mathrm{eV}$, i.e., on $100 \mathrm{k} \$$ p.a. We hired two very capable engineers and other personnel: Joe Shuler, who had just completed work on the $1 \mathrm{MeV}$ RCA commercial microscope that had been delivered to US Steel in Monroeville, Pa., and Gerry Marsh, whom we knew from his work in the Central Electronic lab of the Fermi Institute. Moreover, there was one mechanic working for Joe in the Central Shop of the Institute as well as occasional student help. Our philosophy could be described as follows: "Relatively low costs can be attained by buying from experienced manufacturers rather than favoring or forcing our own design." We searched and found the right outfits, which would muster all their experience to fulfill our desire for a compact design. Fixed designs come with fixed prices, and thus the granting agency could be provided with a firm idea of its commitment.

\section{2. $1 \mathrm{MeV}$ stem design}

\subsubsection{Tanks and vessels}

All the high voltage vessels of the STEM were pieces of standard high-pressure water pipes of $30 \mathrm{in}$. diameter, using readily available fitting caps. The entire assembly consisted of two common Ts usually applied for connecting three pipes.

In operation, the assembled Double-T was to be filled with isolating gas SF6, pressurized to 6 atm-90 psi (Fig. 4). The vertical pipe of the left $\mathrm{T}$ contained the High Voltage Power supply whereas that of the right $T$ housed the microscope column consisting of electron gun and accelerator tube. Through the horizontal pipes of the Double-T ran a corona-shielded cylindrical assembly of the surge resistor, housing for the electron gun plus ion-pumps and the sampling resistor, which was bolted to the right end-cap (Fig. 5).

\subsubsection{High voltage power supplies}

The remarkable cascade transformer was designed and built by Deltaray Corporation (a subsidiary of High Voltage Engineering Corp., Boston). It consisted of 27 modules, each completely encapsulated in epoxy, having a thickness of $3.9 \mathrm{~cm}$ and a diameter of $25 \mathrm{~cm}$ and containing transformer coils, capacitors and a voltage multiplier generating $40 \mathrm{kV} \mathrm{DC}$.

To build up the DC voltage, the decks (modules) were stacked one on top of another, just like flashlight batteries (Fig. 6). The 


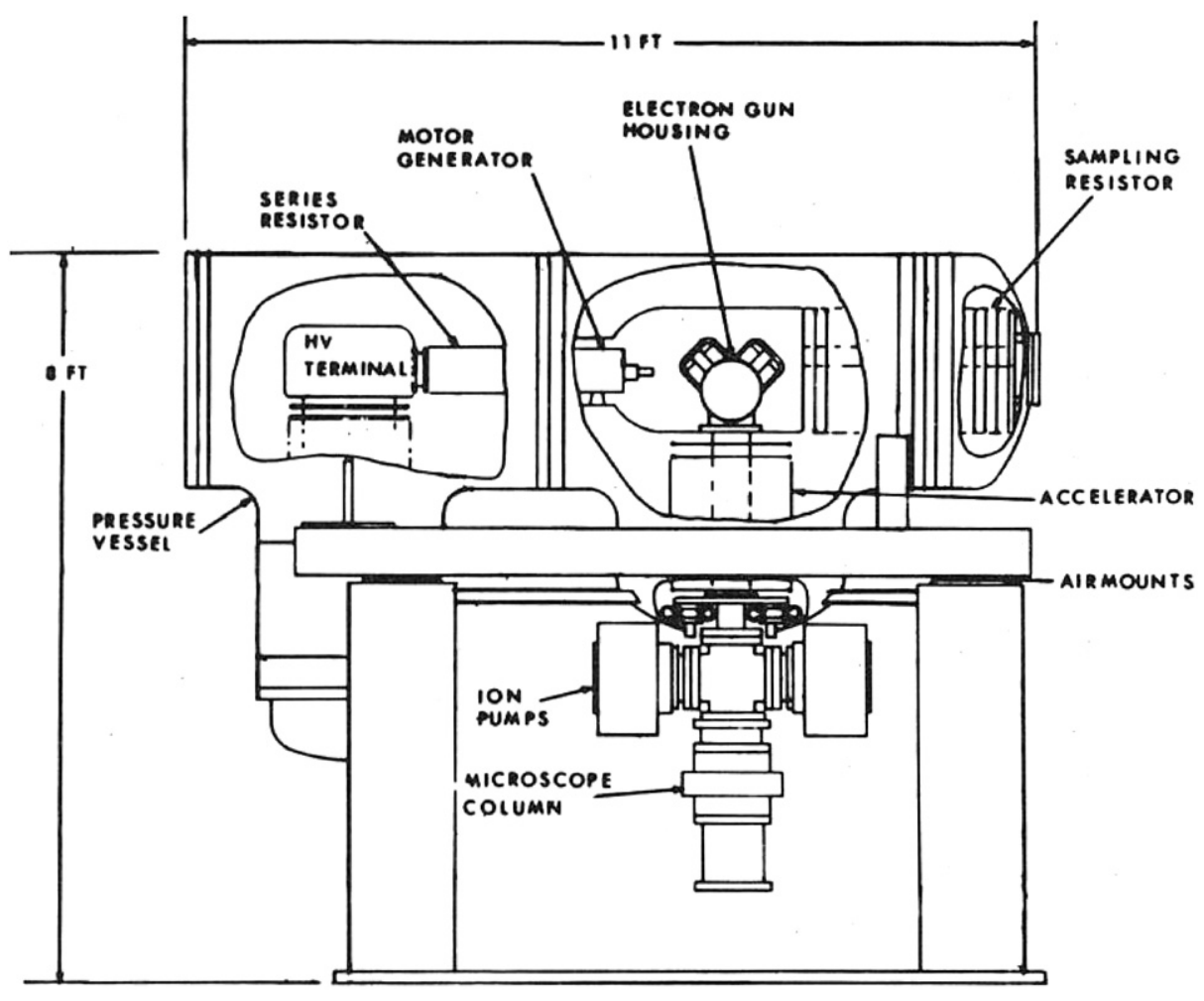

Fig. 4. Overall design of the $1 \mathrm{MeV}$ STEM.

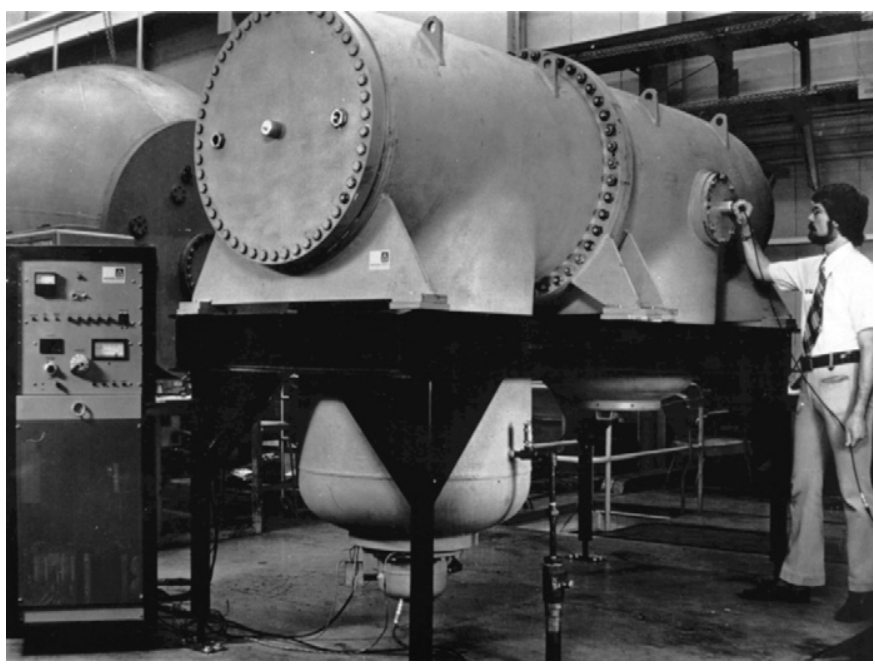

Fig. 5. Real thing on a preliminary support.

strip on the lower deck was the minus-pole to be connected to the plus-pole of the upper one. The spider transformer delivered the RF supply to the adjacent deck. The assembled stack sat in the left $\mathrm{T}$.

During a first test, the power supply in the SF6-pressurized Double-T $(6 \mathrm{~atm})$ reached $1100 \mathrm{kV}$ within one minute, without the accelerator in place; with it in place, the anode conditioning procedure required several hours. Since the STEM was designed for operating in the range of $100-1000 \mathrm{kV}$, the power supply could be set in $1 \mathrm{kV}$ steps at any voltage within the range. The high voltage was brought to the gun via the surge resistor. To avoid interference

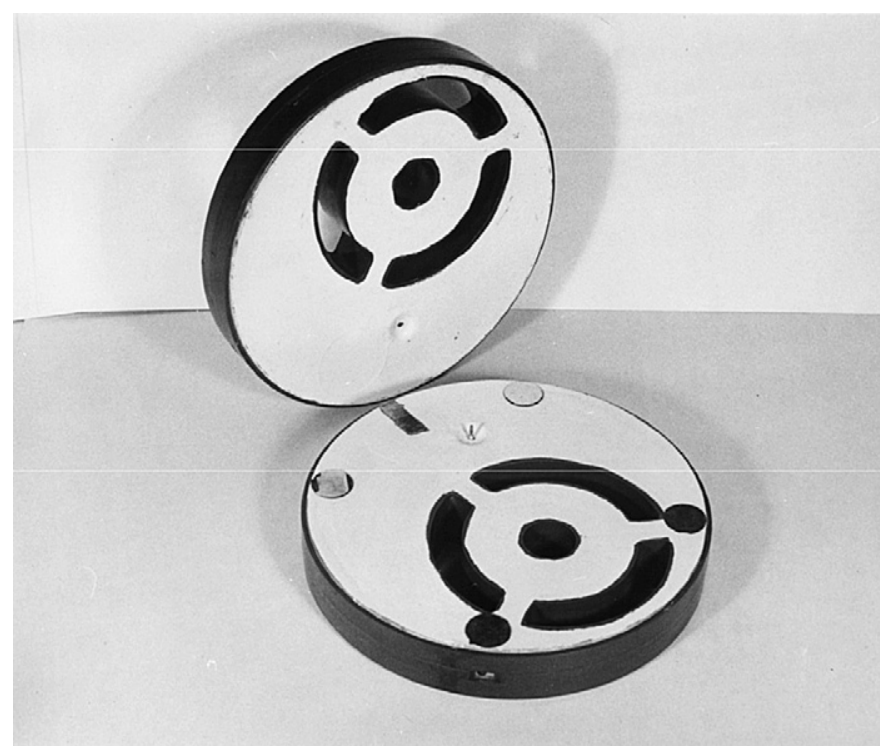

Fig. 6. Two $40 \mathrm{kV}$ DC modules to be stacked.

from the supply, the sampling resistor measuring the gun voltage was located in the right end-cap.

\subsubsection{Field emission gun}

For high-performance field emitters, excellent vacuum is essential. This vacuum of $10^{-10}$ Torr was provided by two $25 \mathrm{l} / \mathrm{s}$ ion pumps. They could be powered either by a gas turbine generator or by batteries; both sources were housed in the corona shield. The mechanical positioning in $x, y$ and $z$ directions of the 
emitter was done by stepper motors, which moved a stage similar to a top-entry stage of a conventional EM. The replacement of a field emitter in the pressurized high voltage tank promised to be tedious, and although the lifetime of a field emitter in normal use is of the order of one year, we found from experience that a supply of several tips within the gun housing was mandatory for the initiation of the scope. To fulfill this need for several tips, a Ferris wheel was designed which could accept eight tips at a time. The tips were mounted on small rectangular insulators, which were held by two studs. The insulator chips snapped into channels separated by the spokes of a Ferris wheel (Fig. 7). Retention of the Ferris wheel was achieved by springs, which, in turn, served as contacts when the tip was to be cleaned and reformed by a current pulse.

\subsubsection{Accelerating tube}

The accelerating tube (Fig. 8) was designed and built by the Electrostatics Corp. of Madison WI. It had an all-metal+ceramics construction in three sections. Each tube section consisted of thirteen ceramic rings, inner diameter 4 in., outer diameter $4 \frac{3}{8}$ in., bonded to metal subdivision rings to provide a $1 / 2$ in. thick ring module. Metal rings were arranged to hold detachable cupped titanium electrode inserts, which shielded the ceramic surfaces. Metal to ceramic bonds were made with a metal. Tube sections

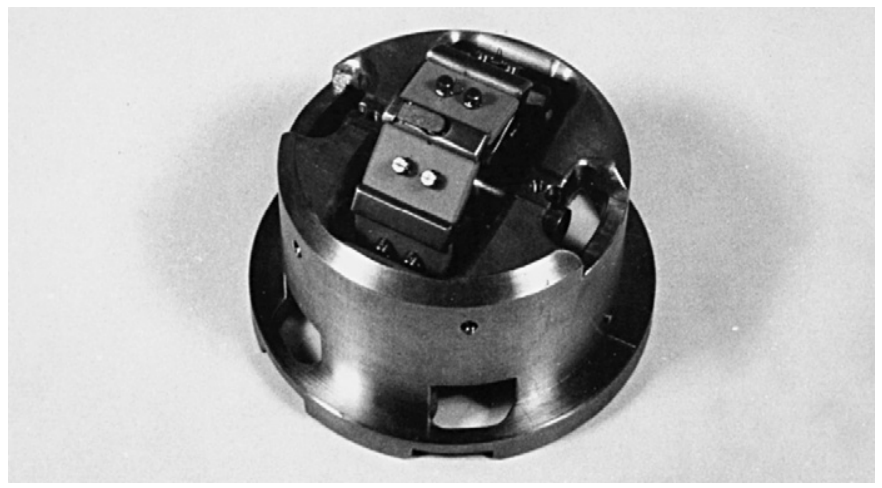

Fig. 7. Ferris wheel for holding multiple field emission tips.

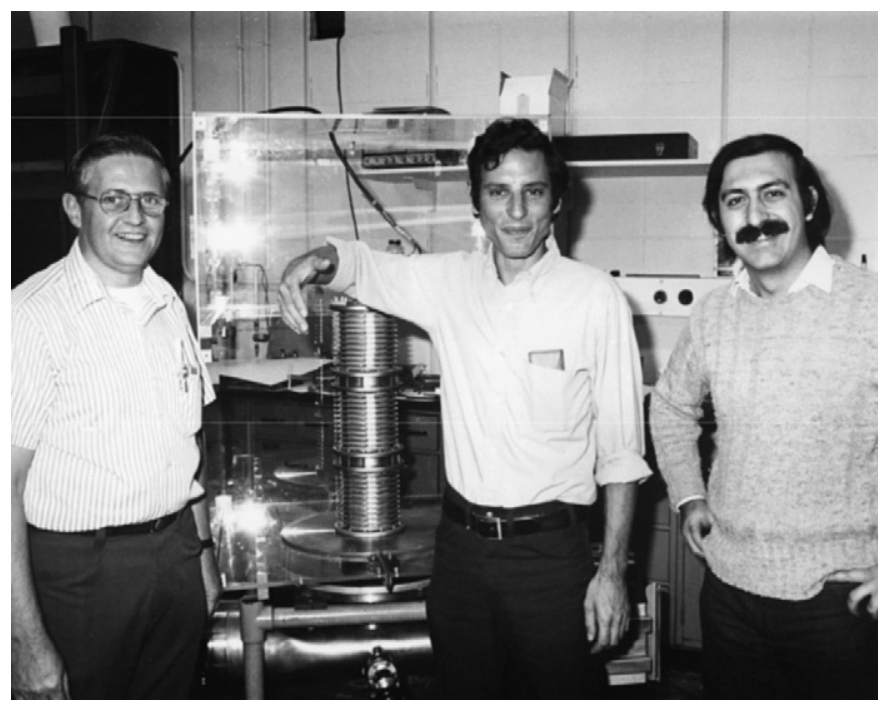

Fig. 8. Joe Shuler, Gerry Marsh and Dimitrios in front of the bare accelerator tube.

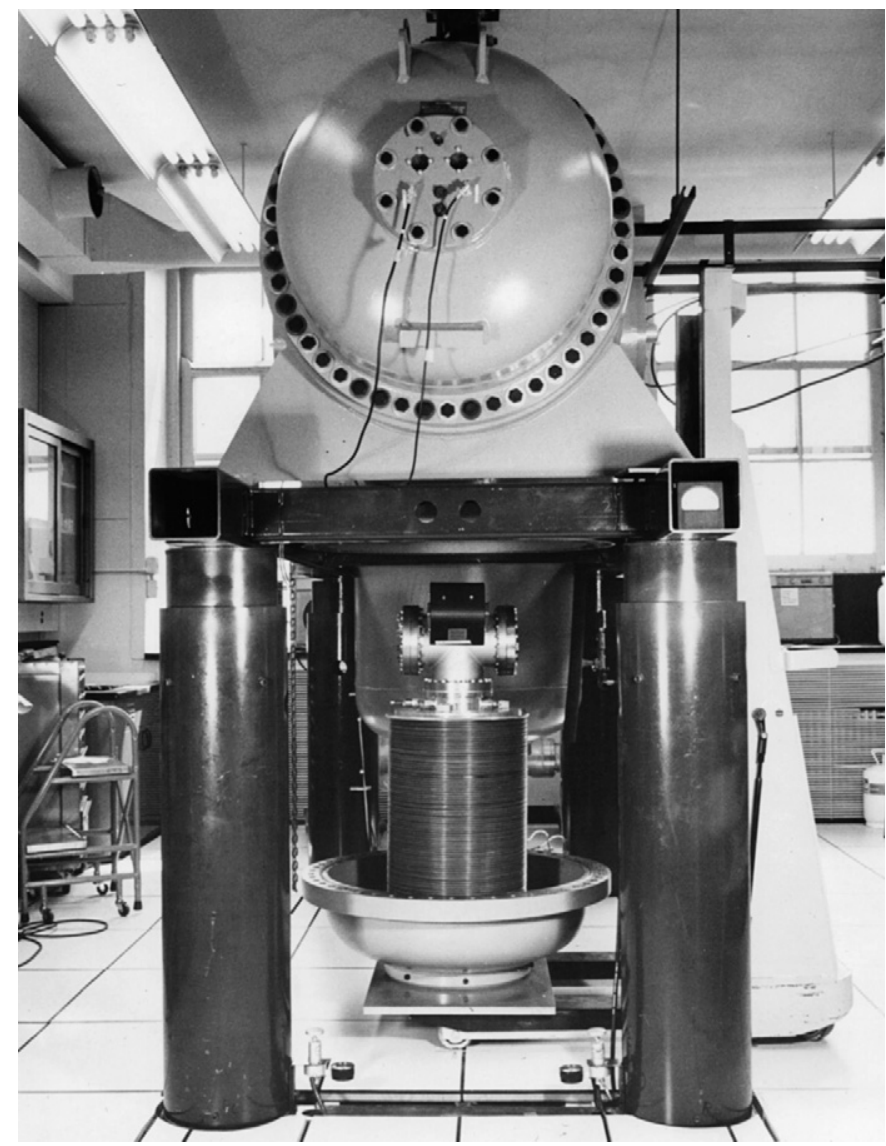

Fig. 9. High voltage beam tube of the microscope column, ready for insertion.

were bolted together and were sealed with metal gaskets. Tube electrodes had openings of approximately $2 \frac{1}{2}$ in. Diaphragms in decoupling sections had openings of 1 in. diameter. Open regions around the diaphragms were provided for pumping. The overall length of the accelerating tube was $22 \frac{3}{8}$ in. The outstanding performance of this accelerator and a larger one constructed for the Dept. of Nuclear Engineering, University of Wisconsin, made us very confident.

The accelerating tube was bakeable up to $200{ }^{\circ} \mathrm{C}$. An internal vacuum of better than $2 \times 10^{-10}$ Torr was readily maintained with the aid of two $200 \mathrm{l} / \mathrm{s}$ ion pumps, while the external pressure of the insulating gas was 90 psi. A potential-grading column added in Chicago assured an uniform electric potential along the accelerator, and fulfilled two more functions: magnetic shielding and high voltage (HT) stabilization. Each equipotential electrode, made of mu-metal, consisted of two concentric hoops whose outermost diameter was $16 \mathrm{in}$. and whose innermost diameter just cleared the accelerator. A gap of $1 \frac{1}{2}$ in. between the hoops allowed for a chain of resistors to spiral along the column and improved the shielding effect of the mu metal. The capacity between neighboring hoops contributed to the HT stability [16].

Fig. 9 shows the assembled accelerator with the magnetic shielding fixed to the cap, ready to be heaved through the porthole above in the right $\mathrm{T}$. The picture allows an appreciation of the dimensions. The connection of the accelerator to the outside was effected by a feed-through that resembled a pressurized rubber doughnut and served as an anti-vibration device (Fig. 10). Together with the ion pumps on top of the electron optical column, the accelerator formed an inverted pendulum, which gently swung on the doughnut. 


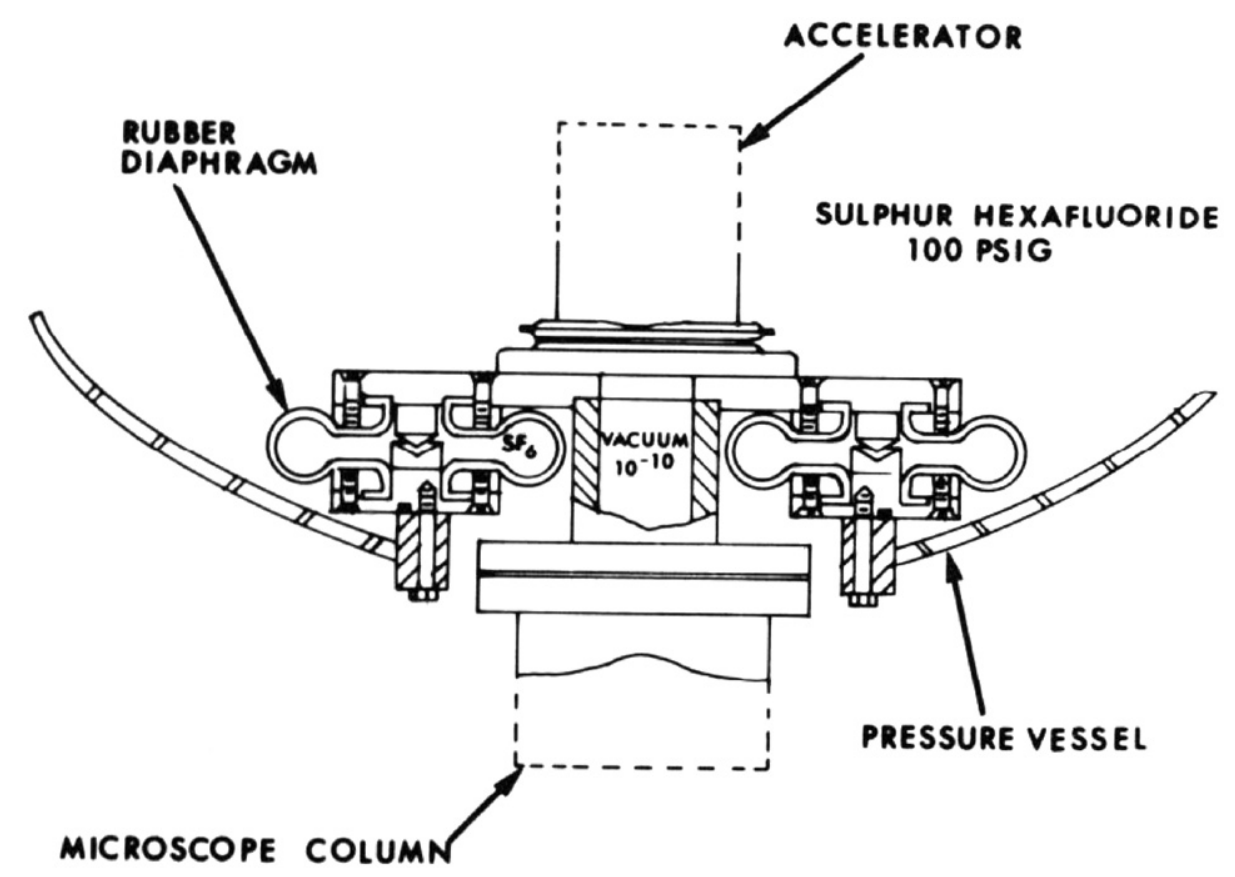

Fig. 10. Air-mount feed-through of microscope column-the "Doughnut".

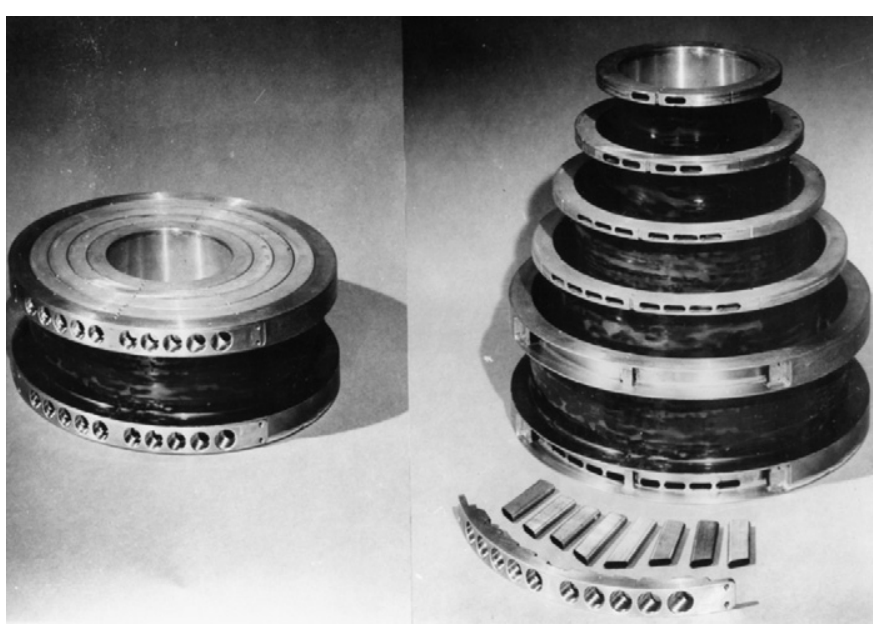

Fig. 11. Objective lens: Divided windings and water-cooling system.

\subsubsection{Electron lenses}

For the sake of versatility, a weak injector lens was built right into the anode of the gun. By this combination, the conditions governing field emission and the optics of the accelerator were uncoupled and the optics could be optimized; together with the scanning system these components could be run as a simple "gun microscope". The probe-forming (objective) lens, 12 in. in diameter and $11 \mathrm{in}$. in length, was excited to 40,000 A turns. With a gap of $7 \mathrm{~mm}$ and a bore of $3 \mathrm{~mm}$, this lens according to Butler's calculations was to have a focal length $6 \mathrm{~mm}$ and spherical and chromatic aberration constants of $3 \mathrm{~mm}$ and $5 \mathrm{~mm}$, respectively. The heat in the coil resulting from the high current density was dissipated effectively by dividing the winding into several coils with individual cooling surfaces (Fig. 11). In retrospect, our cooling measures could have been milder.

Fig. 12 shows the two $200 \mathrm{l} / \mathrm{s}$ ion pumps that evacuated the microscope column, sitting above the objective lens that was supported by a shelf.

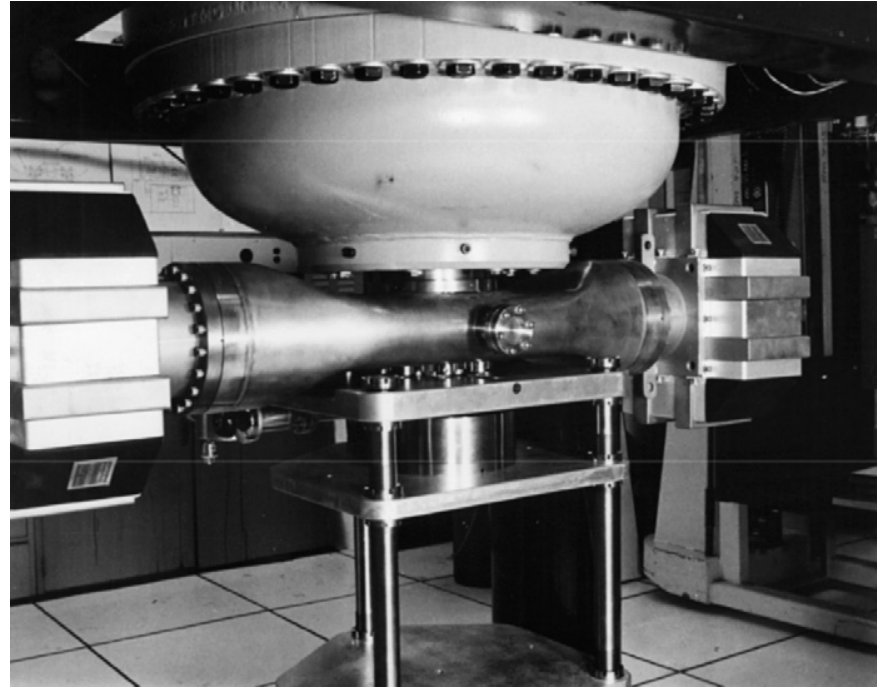

Fig. 12. Down to earth. The microscope from the accelerator to the objective lens, resting on its shelf.

\subsection{Albert becomes Principal Investigator}

In the fall of 1976, during the fifth year of our grant, I received an unexpected, unique and tempting offer from the Max Planck Society to become Ernst Ruska's successor as director at the FritzHaber Institute in Berlin. Only first generation immigrants can have a feeling for the kind of decision that was asked of me. It was not based on reason and brain, but rather on emotion and heart. In the summer of 1977 we moved to Berlin ${ }^{2}$.

${ }^{2}$ In 1986 Ruska, as inventor of the Electron Microscope and by then an octogenarian, shared the Nobel Prize for Physics with Binnig and Rohrer, the inventors of the Scanning Tunneling Microscope. 
I discussed this offer and, in particular, my intentions with regard to our grant, with Albert. The report above describes his fruitful involvement, so that I could count on his takeover of the role of Principal Investigator with all its bureaucratic ramifications. Instead of a last fifth of the total grant, there was only $85-90 \mathrm{k} \$$ left, certainly sufficient for the salaries. A renewal of the grant application was imminent.

Unfortunately, the grant was not renewed. The explanation may be found in Albert's personal recollections [17] from which I quote the following remarks:

"I have mentioned the funding problem several times now and I would like to add some comments on the subject: The first thing to be said is that the work in the early years was generously supported by the DOE and the predecessors, but later we encountered a situation where there was no U.S. government agency that supported instrument development for its own sake. All agencies insisted upon having specific uses for any instrument project. Generalizations were not acceptable. It was useless to suggest that improved resolution is always needed and generates its own uses. Such statements were unacceptable. Galileo could never have been funded if these rules were applied. He knew nothing of the moons of Jupiter before he had a look at the planet. Similarly Hooke, who made the most useful discovery in biology-the cell-did not know that they were there until he looked.

On the other hand, one could argue that it is entirely reasonable to insist on having a specific use in mind for a new instrument. In principle this sounds good, but there are some drawbacks. One of these is that the reviewers were from the community of appropriate users. In my case, this has meant that the proposals are reviewed by biologists, who in general are not experts in microscope designs or in solutions of second-order differential equations. In fact, I have had two good proposals turned down because one of the reviewers gave a negative review [after he] started out by saying: 'I know nothing about this subject but...', and then he proceeded to prove it. Hardly a peer review!"

\section{Conclusion}

I would like to end this report with a copy of a letter of support on behalf of Albert, which I was asked to send to the President's Committee on the National Medal of Science, National Science Foundation Washington, DC (Appendix A). The letter reflects my high esteem and respect for Albert as a scientist and colleague.

Deeply indebted and in grateful reverence, I will remember Albert as a unique and unforgettable friend.

\section{Appendix A.}

\section{FRITZ-HABER-INSTITUT DER MAX-PLANCK-GESELLSCHAFT}

Abteilung Elekronenmikroskopie

Direktor: Prof. Dr. E. Zeitler

\author{
Faradayweg 4-6 \\ D-1000 Berlin 33 (Dahlem) \\ Tel.: (030) 83 05-341 \\ Telex: 185676 fhimp-d \\ 23 August 1988
}

President's Committee on the, National Medal of Science, National Science Foundation, Washington, D.C. 20550

Gentlemen:

I wish to support the nomination of Albert Crewe for the National Medal of Science. Through my collaboration with Crewe during the years 1968-77 at The University of Chicago I have a privileged knowledge of the man, his capabilities and his achievements.

Professor Crewe's great ability to inspire leading scientists was recognized early and confirmed in making him, at the age of 34 , director of the Argonne National Laboratory. Having been in the forefront of development of high energy accelerators, where the most modern technology is applied to advance the state of the art, he foresaw with great imagination that the field of electron microscopy could profit greatly if the modern technology available in accelerator science were applied to advance the instruments. Since both accelerator and electron microscope are akin, he succeeded, in a single pioneering effort, in developing a transmission scanning microscope which has many advantages over the conventional microscope, and he singlehandedly convinced the whole scientific community that his prototype is superior to any commercially available microscope. Indeed it was the first microscope to show single atoms. By now many manufacturers have emulated this instrument.

In the meantime, surface science has become a new, fastdeveloping field in science because it promises to find and understand new materials and specific catalysts, both in demand for the solution of man's problems. This new research requires that the samples be investigated under ultra-high-vacuum conditions. This, however, was also the dominating prerequisite Crewe imposed on the design of his scanning electron microscope. It is no wonder that ultra-high-vacuum scanners, together with auxiliary instrumentation, became the central facilities in any materials science laboratory. Again Crewe has crucially influenced the development of a whole field in science.

It is for his insight and vision and for his imaginative and persistent pursuit of the creation of his instrument and its successful application that I support the nomination of Albert Crewe to receive the National Medal of Science. 


\section{References}

[1] M.S. Isaacson, D.E. Johnson, Simple Scanning Electron Microscope, Review of Scientific Instruments 40 (1969) 241.

[2] P.W. Hawkes, Judith Reiffel (1931-2002): life and letters, Ultramicroscopy 102 (2005) 173-180.

[3] L. Gandolfi, J. Reiffel, Enhancement of contrast in the CEM and STEM using bumpy specimens and employing the 'Dappled Field' mode of operation, in: Proceedings of the 32nd Annual Meeting, EMSA, 1974, p. 552.

[4] G.F. Bahr, E.H. Zeitler (Eds.), Proceedings of the Symposium on Quantitative Electron Microscopy, Armed Forces Institute of Pathology); also published in Laboratory of Investigation 14 (1965) 739-1334.

[5] J.M. Cowley, Image contrast in a Transmission Scanning Electron Microscope, Applied Physics Letters 15 (1969) 58.

[6] A.V. Crewe, J. Wall, Contrast in a High Resolution Scanning Transmission Electron Microscope, Optik 30 (1970) 461-474.

[7] E. Zeitler, M.G.R. Thomson, Scanning Transmission Electron Microscopy I and II, Optik 31 (1970) 258-280, and 359-366.

[8] M.G.R. Thomson, Resolution and contrast in the Conventional and the Scanning Transmission Electron Microscope, Optik 39 (1973) 15-38.

[9] J.P. Langmore, J. Wall, M.S. Isaacson, The collection of scattered electrons in Dark Field Electron Microscopy, Optik 38 (1973) 335-350.
[10] H. Rose, Phase contrast in Scanning Transmission Electron Microscopy, Optik 39 (1974) 416-436.

[11] Humberto Fernandez-Moran, Cryo-Electron Microscopy and Ultramicrotomy: reminiscences and reflections, Advances in Electronics and Electron Physics Supplement 16 (1985) 167-223.

[12] R. Levi-Setti, K.L. Gavrilov, High-Resolution Secondary Ion Mass Spectroscopy Imaging Encyclopedia of Imaging Science and Technology, Wiley \& Sons, NY, 2002. (Chapter 27) p. 47.

[13] J. Munch, Experimental electron holography, Optik 40 (1975) 79-99.

[14] S. Goldstein, E.J. Moerman, K. Porter, High-voltage electron microscopy of human diploid fibroblasts during ageing in vitro: morphometric analysis of mitochondria, Experimental Cell Research 154 (1984) 101-111.

[15] Audrey Glauert, The high voltage Electron Microscope in biology, Journal of Cell Biology 63 (1974) 717-748.

[16] G.E. Marsh, Accelerator system for a $1 \mathrm{MeV}$ STEM, Review of Scientific Instruments 48 (1977) 841-843.

[17] A.V. Crewe, The work of Albert Victor Crewe on the Scanning Transmission Electron Microscope and related topics, Advances in Imaging and Electron Physics 159 (2009) 1-61. 